\title{
Transumbilical laparoendoscopic single-site total mesorectal excision for rectal carcinoma
}

\author{
Maciej Michalik ${ }^{1}$, Maciej Bobowicz ${ }^{1,2}$, Agata Frask ${ }^{1}$, Michał Orlowski ${ }^{1}$ \\ 1Department of General and Vascular Surgery, Ceynowa Hospital, Wejherowo, Poland \\ 2Department of Surgical Oncology, Medical University of Gdansk, Poland
}

Videosurgery and Other Miniinvasive Techniques 2012; 7 (2): 118-121

DOI: $10.5114 /$ wiitm.2011.26756

\begin{abstract}
In recent years, multiple studies have proved laparoscopic total mesorectal excision (TME) to be as safe and as effective in rectal cancer treatment as open surgery, with the undeniable benefit of perioperative trauma reduction. Decreasing the number of incisions and performing single-port surgery could have further reduced the trauma. A new access device, QuadPort ${ }^{T M}$ Olympus, enables operations from just one small transumbilical incision, leaving a barely visible scar afterwards. This is one of the first reports of transumbilical laparoendoscopic single-site TME for rectal carcinoma. A 73-year-old woman presented with tubulo-villous adenoma with high-grade dysplasia and focal adenocarcinoma in situ at $7 \mathrm{~cm}$ from the anal verge. She had TME performed via a QuadPort ${ }^{T M}$, Olympus, in line with principles of laparoscopic TME. The operating time was $80 \mathrm{~min}$. There were no adverse events during the procedure. Total blood loss was less than $100 \mathrm{ml}$. There were no complications in the postoperative period. The patient required only nonopioid analgesia, during the first 2 days. The patient was discharged on the $3^{r d}$ postoperative day with standard recommendations. Feasibility and safety of the proposed transumbilical laparoendoscopic single site TME for rectal carcinoma was proved. It is a technically demanding procedure, requiring appropriate laparoscopic skills. The QuadPort provided good oncological protection of the wound and easy specimen extraction. Reduced operative trauma resulted in no opioid administration in the perioperative period. Hospital stay was comparable with laparoscopic TME but the cosmetic effect was much better.
\end{abstract}

Key words: transumbilical, laparoendoscopic, single-site surgery, total mesorectal excision, rectal cancer, QuadPort, single incision surgery, single port surgery, single access surgery.

\section{Introduction}

Rectal cancer affects numerous patients every year, and due to its location there is usually a huge perioperative trauma burden. Multiple studies have proved laparoscopic total mesorectal excision (TME) to be as safe and as effective in rectal cancer treatment as open surgery, with the undeniable benefit of perioperative trauma reduction [1,2]. Development of new instruments and devices brings new challenges for surgeons who are trying to decrease the perioperative trauma. One of the very promising access devices is the QuadPort ${ }^{\text {TM }}$ Olympus, (Advanced Surgical Concepts, Wicklow, Ireland) laparoendoscopic single-site access system (Figure 1). It enables one to perform operations from just one small transumbilical incision, leaving a barely visible scar afterwards. So far it has been used in such common operations as single incision cholecystectomy but also more complex operations as adrenalectomy, hemicolecto- 
my, distal pancreatic resection and finally in bariatric surgery [3-12]. To the authors' knowledge this is one of the first reports of transumbilical laparoendoscopic single-site (LESS) total mesorectal excision for rectal carcinoma. The authors assess the feasibility, safety and short-term outcomes of a transumbilical LESS TME for rectal carcinoma using a QuadPort ${ }^{\mathrm{TM}}$ access system.

\section{Case report}

The 73-year-old woman was admitted due to rectal bleeding. On examination she was found to have a rectal mass palpable at $7 \mathrm{~cm}$ from the anal verge. Diagnostic colonoscopy and computed tomography confirmed the presence of a large $(28 \mathrm{~mm} \times 25 \mathrm{~mm})$, exophytic rectal mass with a probability of crossing the rectum's border with no local lymphadenopathy or distal metastases. Histopathological examination showed rectal tubulo-villous adenoma with highgrade dysplasia and a high suspicion index for carcinoma development. The patient was slim, with a virgin abdomen. Family history for colorectal cancer was negative.

\section{Technique}

Standard preoperative bowel preparation, antibiotic prophylaxis and antithrombotic prophylaxis as for laparoscopic TME were administered. QuadPort ${ }^{\mathrm{TM}}$, Olympus (Advanced Surgical Concepts, Wicklow, Ireland) was used as an access point. A vertical, $4 \mathrm{~cm}$ long incision through the umbilicus was made. Open technique of port introduction was used. Pneumoperitoneum of up to $12 \mathrm{mmHg}$ was achieved. Ten millimeters laparoscopic camera and $5 \mathrm{~mm}$ harmon-

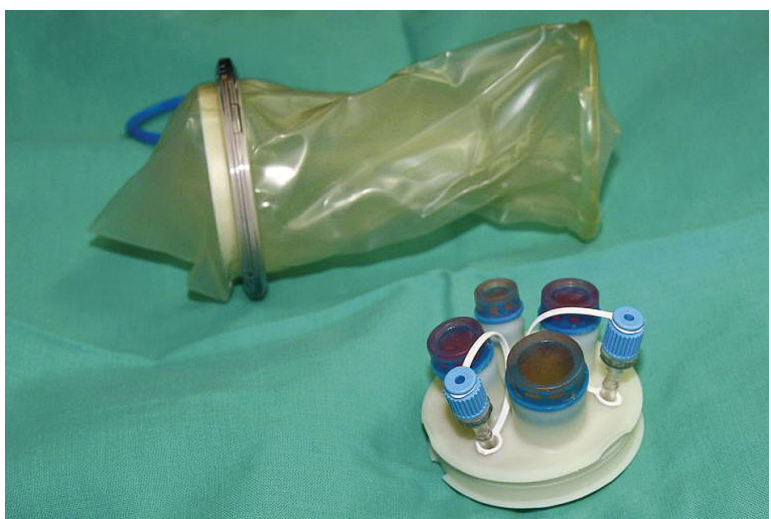

Figure 1. QuadPort ${ }^{\mathrm{TM}}$ Olympus (Advanced Surgical Concepts, Wicklow, Ireland) ic scalpel (Harmonic ACE ${ }^{\circledR}$, Ethicon Endo-Surgery) with standard laparoscopic dissector and graspers were used. Only one pair of curved laparoscopic clinching grasping forceps (Olympus) was used to elevate the uterus and avoid instruments clashing (Figure 2). The standard operative technique as for laparoscopic TME was used with a medial to lateral approach.

The peritoneum was incised with the Harmonic ACE Scalpel. The inferior mesenteric artery was identified and dissected below the left colic artery with the harmonic scalpel (without clipping). Next, the sigmoid and upper rectum with mesorectum were mobilized.

Transection of the rectum was performed with the Echelon Flex $60^{\mathrm{TM}}$ Endopath articulated stapler (Ethicon Endo-Surgery) with the use of two gold cartridges. The pneumoperitoneum was eliminated via removal of the port's boot. The rectum and sigmoid colon were exteriorized through the QuadPort's sleeve without removing the port itself.

The rectal mass was resected with about $10 \mathrm{~cm}$ proximal and $2 \mathrm{~cm}$ distal margins (Figure 3). The anvil of the Proximate ${ }^{\circledR}$ curved intraluminal stapler size $29 \mathrm{~mm}$ (Ethicon Endo-Surgery) was inserted into the proximal colon after purse-string suture fashioning with a purse-string device. The left colon with the anvil were interiorized. The QuadPort's boot was reattached and the pneumoperitoneum was re-insufflated. The anvil was connected with the staplers head and tension-free anastomosis was performed. Proximal and distal rings were checked. Lavage with normal saline was done and a Redon drain was left in situ. Closure of the peritoneum and all layers of the abdominal wall was done with standard suturing material.

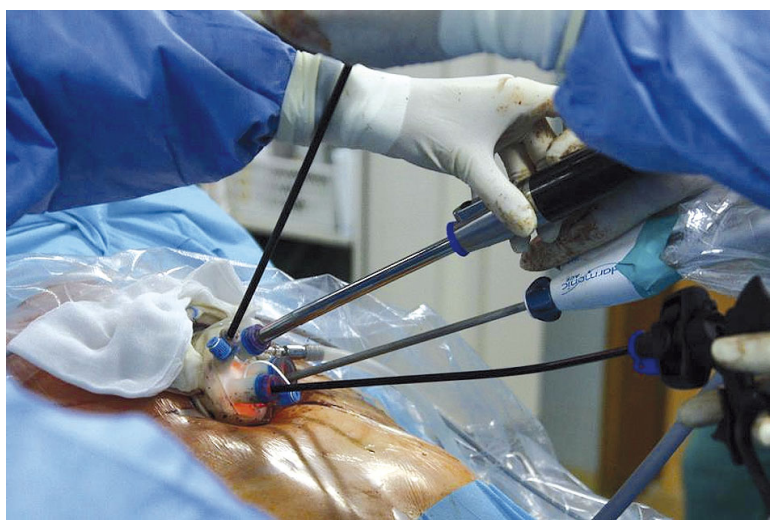

Figure 2. External view of instruments - difficulties with instruments clashing 


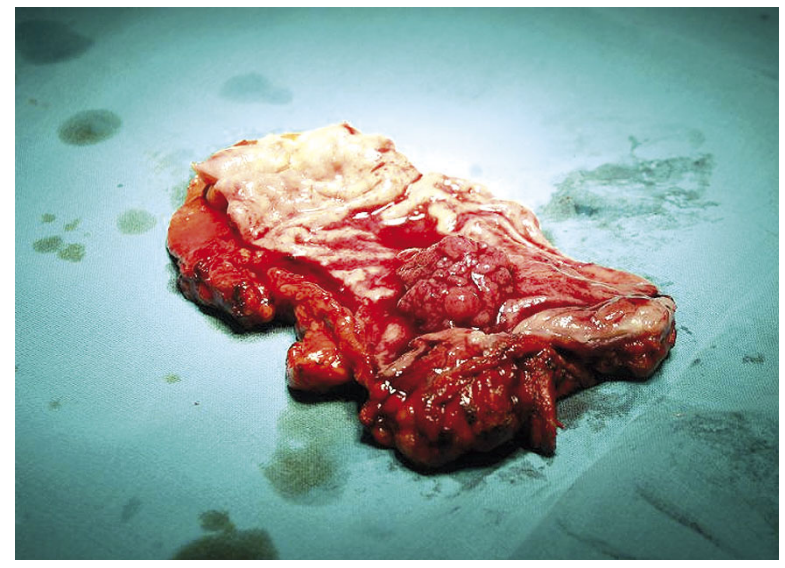

Figure 3. Specimen with exophytic tumour

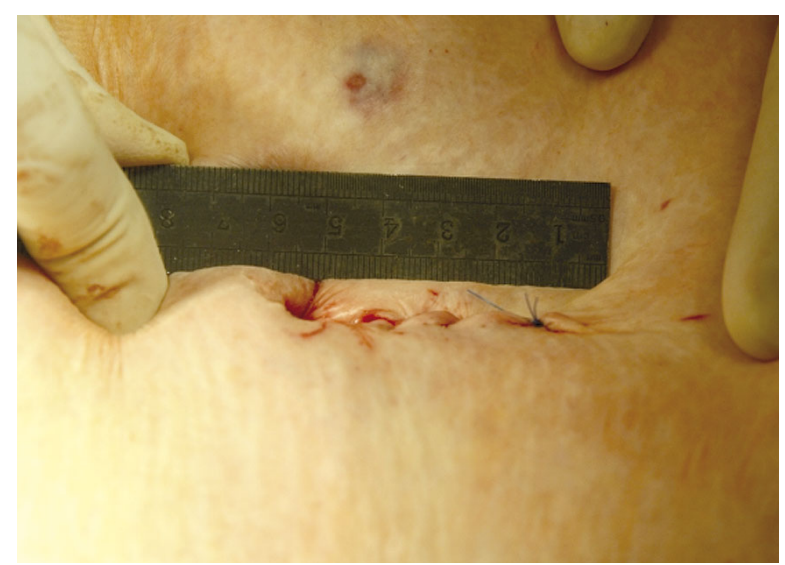

Figure 4. Postoperative scar

\section{Results}

The total operating time was $80 \mathrm{~min}$. There were no adverse events during the procedure. Total blood loss was less than $100 \mathrm{ml}$. The postoperative period was uneventful. The patient was fully mobilized on the $1^{\text {st }}$ postoperative day. The patient required only mild analgesia with ketoprofen and paracetamol for the first 2 days only. Peristalsis returned on the first postoperative day. The same day oral fluids were introduced and the next day a liquid diet was started. The patient tolerated oral nutrition well and was discharged on the third postoperative day with standard recommendations.

Histopathological examination of the specimen showed tubulo-villous adenoma with high-grade dysplasia and focal adenocarcinoma in situ. The specimen's margins and the base of the rectal mass were clear of cancer cells. Examined lymph nodes showed no involvement.

\section{Discussion}

Current progress in minimisation of the operative trauma led to invention of new approaches. One is natural orifice transluminal endoscopic surgery and the other is single incision laparoscopic surgery or single port access surgery (SPA). Single port surgery requires special access devices, though some surgeons invent their own single access devices made of such simple materials as a surgical glove $[13,14]$. One of the newest devices on the market is QuadPort ${ }^{\mathrm{TM}}$, Olympus (Advanced Surgical Concepts, Wicklow, Ireland). QuadPort used as an access point allows one to pass four laparoscopic instruments through one incision simultaneously. This is a great advantage over other devices as most ports are limited to three instruments only. Adjustability of the QuadPort and location of the valves allows easier access and manipulation even with standard, straight laparoscopic instruments. Its detachable boot and sleevelike body protecting the whole thickness of the wound allowed easy and safe extraction of the specimen with regard to oncological principles. Attaching the boot back allowed pneumoperitoneum to be achieved.

Some negative aspects of the QuadPort were encountered. One was the 'chimney effect', where the pneumoperitoneum was leaking along the space between the port's sleeve and the wound as well as the air leak at the port's valves that occurred in the final stages of the operation.

At the most crucial stage when the low anterior rectal division is done, difficulty with instruments' triangulation was diminished by use of the Echelon Flex $^{\mathrm{TM}}$ Endopath articulated stapler. Articulation of the Echelon Flex allowed a correct approach angle unavailable with any linear stapler.

Both the short operative time and limited blood loss were comparable to those of laparoscopic TME. Postoperatively only low doses of non-opioid analgesics were used. The patient was discharged on the $3^{\text {rd }}$ postoperative day with no complications. The 1-month follow-up showed no early complications of the procedure. The cosmetic result was good, with a small $4 \mathrm{~cm}$ long scar, partially concealed in the natural body scar of the umbilicus (Figure 4).

So far there have been few reports on colorectal laparoscopic single port operations. A search of multiple databases returned 11 articles describing 1 case of proctocolectomy [15]; 2 sigmoidectomies [16, 17]; 
3 left colectomies [18-20]; 9 cases (5 articles) of right hemicolectomies [14, 21-24]; but no TME. Therefore, to our knowledge, this is the first report on singleport access total mesorectal excision for malignant disease. It can be a safe procedure with good oncological outcomes in a well-selected group of patients. It reduces perioperative trauma, minimising the use of analgesics, and providing better cosmetic outcome than open and laparoscopic TME.

\section{Conclusions}

Feasibility and safety of the proposed transumbilical laparoendoscopic single-site total mesorectal excision for rectal carcinoma were proved. It is a technically demanding procedure, requiring appropriate laparoscopic skills. Use of advanced access point devices made the procedure easier and safer for the patient. The QuadPort provided good oncological protection of the wound and easy specimen extraction. Reduced operative trauma resulted in no use of opioids in the perioperative period. Hospital stay was comparable to laparoscopic TME but the cosmetic outcome was much improved.

Further studies on larger populations are required for better technique assessment.

\section{References}

1. Leung KL, Kwok SP, Lam SC, et al. Laparoscopic resection of rectosigmoid carcinoma: prospective randomised trial. Lancet 2004; 363: 1187-92.

2. Jayne DG, Guillou PJ, Thorpe H, et al. Randomized trial of laparoscopic-assisted resection of colorectal carcinoma: 3-year results of the UK MRC CLASICC Trial Group. J Clin Oncol 2007; 25: 3061-8.

3. Michalik M, Frask A, Trybull A, et al. Methods of treatment for gallbladder diseases. Videosurgery and Other Miniinvasive Techniques 2009; 4: 121-5.

4. Kurpiewski W, Pesta W, Kowalczyk M, et al. SILS cholecystectomy - our first experiences. Videosurgery and Other Miniinvasive Techniques 2009; 4: 91-4.

5. Wróblewski TM, Piotrowicz S, Kotulski M, et al. No-visible-scar cholecystectomy. Videosurgery and Other Miniinvasive Techniques 2010; 5: 158-60.

6. Łosin M, Czauderna P, Gołębiewski A. Single incision laparoscopic surgery cholecystectomy in children - preliminary experience. Videosurgery and Other Miniinvasive Techniques 2010; 5 : 139-41.

7. Łosin M, Czauderna P, Gołębiewski A, Stefanowicz J. Single incision laparoscopic adrenalectomy - initial experience. Videosurgery and Other Miniinvasive Techniques 2010; 5: 104-6.

8. Budzyński A, Pędziwiatr M, Matłok M, et al. Preliminary experience with transperitoneal single incision laparoscopic surgery adrenalectomy. Videosurgery and Other Miniinvasive Techniques 2010; 5: 87-92.

9. Cywiński J, Kuzdak K, Kołomecki K. One-incision approach (SILS) for retroperitoneal videoscopic adrenalectomy. Videosurgery and Other Miniinvasive Techniques 2010; 5: 70-1.

10. Michalik M, Orłowski M, Frask A, et al. LESS (laparo-endoscopic single-site surgery) right hemicolectomy. Videosurgery and Other Miniinvasive Techniques 2009; 4: 164-7.

11. Michalik M, Bobowicz M, Lech P, Orłowski M. Distal pancreatic resection via laparo-endoscopic single site surgery - development of the technique. Videosurgery and Other Miniinvasive Techniques 2010; 5: 142-5.

12. Bobowicz M, Michalik M, Orłowski M, Frask A. Bariatric single incision laparoscopic surgery - review of initial experience. Videosurgery and Other Miniinvasive Techniques 2011; 6: 48-52.

13. Romanelli JR, Earle DB. Single-port laparoscopic surgery: an overview. Surg Endosc 2009; 23: 1419-27.

14. Choi SI, Lee KY, Park SJ, Lee SH. Single port laparoscopic right hemicolectomy with D3 dissection for advanced colon cancer. World J Gastroenterol 2010; 16: 275-8.

15. Geisler DP, Condon ET, Remzi FH. Single incision laparoscopic total proctocolectomy with ileopouch anal anastomosis. Colorectal Dis 2010; 112: 941-3.

16. Bucher P, Pugin F, Morel P. Transumbilical single incision laparoscopic sigmoidectomy for benign disease. Colorectal Dis 2010; 12: 61-5.

17. Leroy J, Cahill RA, Asakuma M, et al. Single-access laparoscopic sigmoidectomy as definitive surgical management of prior diverticulitis in a human patient. Arch Surg 2009; 144: 173-9.

18. Bucher P, Pugin F, Morel P. Single-port access laparoscopic radical left colectomy in humans. Dis Colon Rectum 2009; 52: 1797-801.

19. Law WL, Fan JK, Poon JT. Single incision laparoscopic left colectomy for carcinoma of distal transverse colon. Colorectal Dis 2010; 12: 698-701.

20. Remzi FH, Kirat HT, Geisler DP. Laparoscopic single-port colectomy for sigmoid cancer. Tech Coloproctol 2010; 14: 253-5.

21. Bucher P, Pugin F, Morel P. Single port access laparoscopic right hemicolectomy. Int J Colorectal Dis 2008; 23: 1013-6.

22. Merchant AM, Lin E. Single-incision laparoscopic right hemicolectomy for a colon mass. Dis Colon Rectum 2009; 52: 1021-4.

23. Remzi FH, Kirat HT, Kaouk JH, Geisler DP. Single-port laparoscopy in colorectal surgery. Colorectal Dis 2008; 10: 823-6.

24. Rieger NA, Lam FF. Single-incision laparoscopically assisted colectomy using standard laparoscopic instrumentation. Surg Endosc 2010; 24: 888-90. 